\title{
Leucine-Rich Repeat Kinase 2 Gene-Associated Disease: Redefining Genotype-Phenotype Correlation
}

\author{
Christian Wider $^{\mathrm{a}}$ Dennis W. Dickson ${ }^{\mathrm{b}}$ Zbigniew K. Wszolek ${ }^{\mathrm{a}}$ \\ Departments of a Neurology, and ${ }^{b}$ Neuropathology, Mayo Clinic, Jacksonville, Fla., USA
}

\section{Key Words}

Leucine-rich repeat kinase 2 gene • Parkinson's disease • Lewy body disease $\cdot$ Progressive supranuclear gaze palsy . Nigral degeneration

\begin{abstract}
Background: Leucine-rich repeat kinase 2 (LRRK2) has emerged as the most prevalent genetic cause of Parkinson's disease (PD) among Caucasians. Patients carrying an LRRK2 mutation display significant variability of clinical and pathologic phenotypes across and within affected families. Methods: Herein, we review available clinical and pathologic data on patients with an LRRK2 mutation who have come to autopsy. Results: Thirty-eight patients have been reported who presented clinically with PD; parkinsonism with resistance to levodopa, supranuclear gaze palsy, or autonomic dysfunction; or tremor and dementia. Pathology showed typical PD-type Lewy body disease (LBD) in most patients, whereas in others there was 'pure' nigral degeneration (one with TDP-43-positive inclusions), diffuse LBD, or tau-, $\alpha$ synuclein- or ubiquitin-positive pathology reminiscent of progressive supranuclear gaze palsy, multisystem atrophy, and frontotemporal dementia with ubiquitin-positive inclusions. Conclusions: Such clinical and pathologic variability suggests Lrrk2 acts upstream from other proteins implicated in neurodegeneration. Specific mutations may be associat-
\end{abstract}

ed with alternative progressive supranuclear gaze palsy-like or 'pure' nigral degeneration phenotypes. A different effect on Lrrk2 kinase activity may play a role in such heterogeneity.

Copyright ๑ 2010 S. Karger AG, Basel

\section{Introduction}

Major breakthroughs in the genetics of Parkinson's disease (PD) have dramatically altered our understanding of the mechanisms leading to neurodegeneration [1]. As the number of genes and loci implicated in PD increased over the past decade, it has become clear that genetic factors play a significant role in risk for both sporadic and familial PD. However, such discoveries have also highlighted the clinical and pathologic variability associated with genetically determined PD. Mutations in the leucine-rich repeat kinase 2 (LRRK2) gene have emerged as the major genetic determinants of PD in Caucasian populations [2]. Yet carriers of a given LRRK2 mutation even from the same family can differ in both their clinical and pathologic presentations [3]. Herein we discuss the implications of recent genetic discoveries for genotype-phenotype correlations in LRRK2-associated disease. 
Table 1. Characteristics of $L R R K 2$-associated conditions with reported pathology

\begin{tabular}{|c|c|c|c|c|c|c|}
\hline First author and year & $\begin{array}{l}\text { Name of } \\
\text { family }\end{array}$ & $\begin{array}{l}\mathrm{Pa}- \\
\text { tients }\end{array}$ & $\begin{array}{l}\text { Lrrk2 (p.) } \\
\text { mutation }\end{array}$ & $\begin{array}{l}\text { Age at on- } \\
\text { set, years }\end{array}$ & Clinical features & Pathology ${ }^{1}$ \\
\hline \multirow[t]{2}{*}{$\begin{array}{l}\text { Wszolek, 1997, 2004; } \\
\text { Zimprich, } 2004\end{array}$} & $\mathrm{D}$ & 4 & R1441C & $48-78$ & $\mathrm{P}^{2}(3), \mathrm{P}+\mathrm{S}(1)$ & $\begin{array}{l}\text { BLBD (1), DLBD (1), NFT (1), } \\
\text { ND-Ub-TDP-43 (1) }\end{array}$ \\
\hline & $\mathrm{A}$ & 2 & Y1699C & $51-56$ & $P(1), P+A(1)$ & $\mathrm{ND}-\mathrm{Ub}^{3}$ \\
\hline Khan, 2005 & Lincolnshire & 1 & Y1699C & 50 & $\mathrm{P}$ & LBD (few cortical LB) \\
\hline Gilks, 2005 & - & 3 & G2019S & $41-70$ & $\mathrm{P}$ & $\mathrm{LBD}^{4}$ \\
\hline Rajput, 2006 & SK & 1 & G2019S & 78 & $\mathrm{P}^{5}$ & NFT \\
\hline Ross, 2006 & - & 8 & G2019S & $41-79$ & $\begin{array}{l}\mathrm{P}(3), P+A u(2), P+A u+D(1) \\
D L B+A u(1), D L B(1)\end{array}$ & $\operatorname{BLBD}(4), \operatorname{TLBD}(3)^{6}, \operatorname{DLBD}(1)$ \\
\hline Giasson, 2006 & - & 3 & G2019S & $47-76$ & $\mathrm{P}(2)^{7}, \mathrm{P}+\mathrm{D}(1)$ & $\operatorname{LBD}(2)^{8}, \mathrm{ND}^{9}$ \\
\hline Dachsel, 2007 & - & 1 & G2019S & NR & $\mathrm{D}, \mathrm{T}$ & FTLD-U pathology \\
\hline Gaig, 2007 & - & 1 & G2019S & 61 & $\mathrm{P}$ & ND \\
\hline Gaig, 2008 & - & 1 & G2019S & 51 & $\mathrm{P}$ & LBD (few cortical LB) \\
\hline Chen-Plotkin, 2008 & - & 3 & G2019S & $47-76$ & $\mathrm{P}$ & LBD (diagnosis: PD) \\
\hline \multirow{2}{*}{ Santpere, 2009} & - & 1 & G2019S & NR & $\mathrm{P}$ & $\mathrm{LB}$ in $\mathrm{SN}$ \\
\hline & - & 1 & $\mathrm{R} 1441 \mathrm{G}$ & NR & $\mathrm{P}$ & ND \\
\hline Hasegawa, 2009 & Sagamihara & 8 & $\mathrm{I} 2020 \mathrm{~T}$ & $40-74$ & $\mathrm{P}$ & ND (6), ND-GCI (1), BLBD (1) \\
\hline
\end{tabular}

Figures in parentheses indicate number of cases. $\mathrm{A}=$ Amyotrophy with fasciculations; $\mathrm{Au}=$ autonomic dysfunction; $\mathrm{D}=\mathrm{de}-$ mentia; LB = Lewy bodies; ND = nigral degeneration; ND-GCI = nigral degeneration with $\alpha$-synuclein-positive glial cytoplasmic inclusions (i.e. multisystem atrophy pathology); $\mathrm{ND}-\mathrm{Ub}=$ nigral degeneration with ubiquitin-positive cytoplasmic and nuclear inclusions; NFT = neurofibrillary tangles, pathology reminiscent of progressive supranuclear gaze palsy; $\mathrm{NR}=$ not reported; $\mathrm{P}=$ levodopa-responsive parkinsonism similar to that of idiopathic Parkinson's disease; $\mathrm{S}=$ supranuclear gaze palsy; $\mathrm{SN}$ = substantia nigra; $\mathrm{T}=$ tremor; $\mathrm{TLBD}=$ transitional Lewy body disease.
${ }^{1}$ All patients had SN neuronal loss and gliosis. ${ }^{2}$ One patient died before levodopa became available. ${ }^{3}$ One patient with concurrent $\mathrm{AD}$ pathology, and 1 with mild motor neuron loss in lumbar spinal cord. ${ }^{4}$ Two with LB in limbic cortex, 1 with mild AD pathology. ${ }^{5}$ Poor response to levodopa. ${ }^{6}$ One with concurrent AD pathology. ${ }^{7}$ One did not tolerate levodopa. ${ }^{8}$ One with concurrent $\mathrm{AD}$ pathology, and $\mathrm{LB}$ and Lewy neurites in the neocortex, and 1 with sparse LB, senile plaques and NFT in neocortex. ${ }^{9}$ Rare NFT and senile plaques in neocortex.

\section{LRRK2-Associated PD}

The most prevalent mutation in LRRK2 (p.G2019S) accounts for $1-2 \%$ of sporadic PD and about $5 \%$ of familial PD in populations of European descent. Figures rise to $10-40 \%$ among North-African Arabs and Ashkenazi Jews, whereas Lrrk2 p.G2019S is almost absent in Asian populations. Over forty $L R R K 2$ variants have been identified in PD patients, but only six of them (p.R1441C, p.R1441G, p.R1441H, p.Y1699C, p.G2019S, and p.I2020T) have been established as definitely pathogenic [4]. The penetrance is reduced and age dependent, with $\sim 75 \%$ of mutation carriers displaying clinical PD by age $80[1$, 5]. Two common variants in LRRK2 (p.G2385R and p.R1628P) were found to increase risk for sporadic PD in Asian populations $[6,7]$.
Clinically, the majority of PD patients carrying a mutation in LRRK2 display classic levodopa-responsive lateonset parkinsonism similar to that of idiopathic PD, although a more benign course has been suggested [5]. However, there are notable exceptions. In two of the families that led to the discovery of $L R R K 2$, some patients presented with atypical features such as amyotrophy and fasciculations, autonomic dysfunction, supranuclear gaze palsy, dystonia or dementia [8,9]. Additionally, patients with the Lrrk2 p.G2019S and p.R1441H mutations have been reported with variable phenotypes including corticobasal syndrome [10], progressive supranuclear gaze palsy (PSP) [11], dementia with tremor [12] and levodoparesistant parkinsonism [13]. 

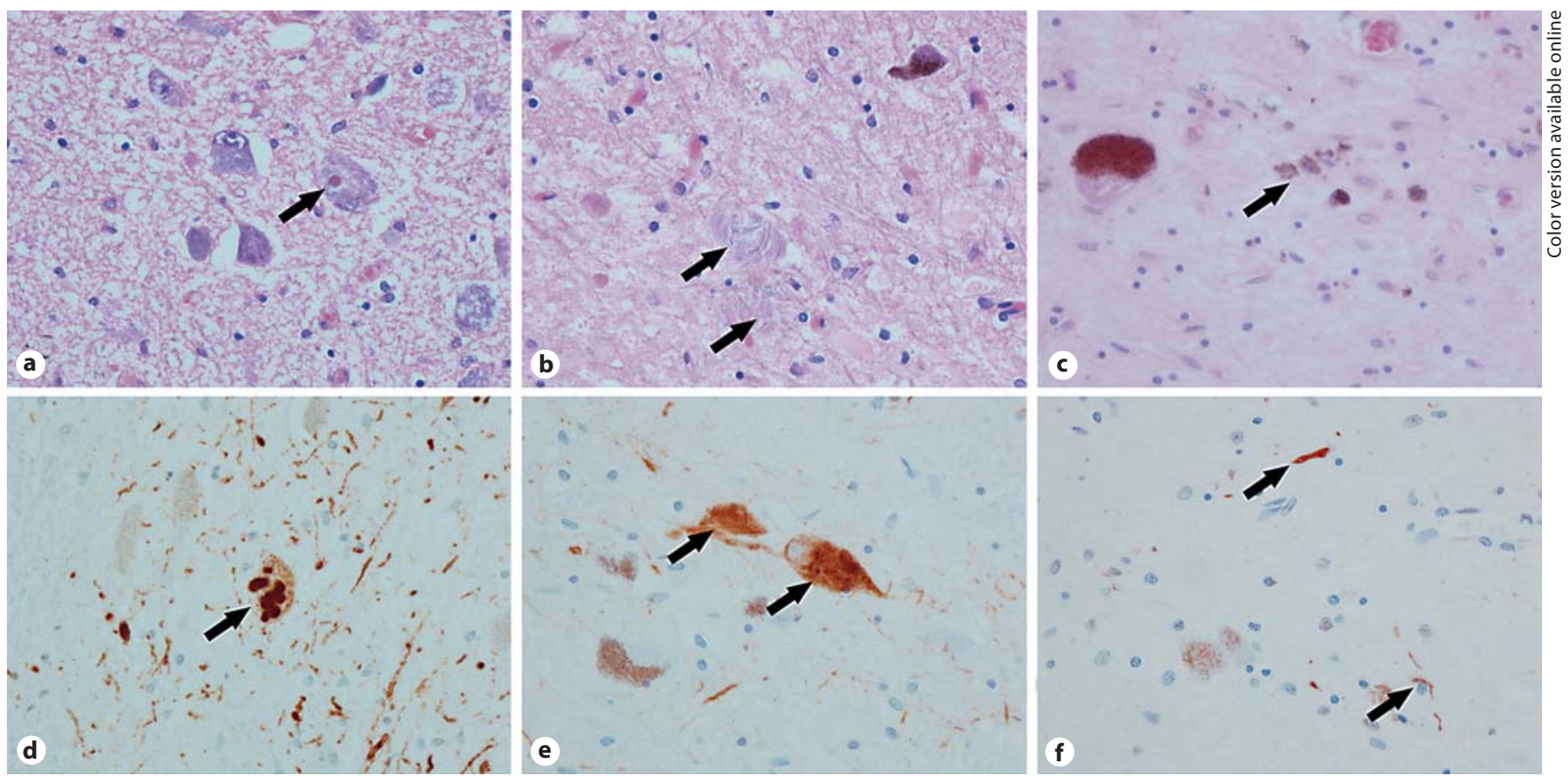

Fig. 1. Histology and immunohistochemistry of 4 PD patients from family D carrying the Lrrk2 p.R1441C mutation. a, d DLBD. b, e Tauopathy. c, f 'Pure' nigral degeneration. a Lewy body in periaqueductal gray (arrow; HE). b Extracellular neurofibrillary tangles (arrows; HE) in substantia nigra. c Nonspecific neuronal loss with neuromelanin in macrophages (arrow; HE). d Lewy bodies in periaqueductal gray (arrow; $\alpha$-synuclein). e Neurofibrillary tangles in substantia nigra (arrows; phospho-tau). f Neurites in substantia nigra (arrows; TDP-43).

\section{Neuropathology of LRRK2 Mutation Carriers}

Only 38 autopsies of diseased individuals carrying a proven pathogenic LRRK2 mutation have been reported so far (table 1; fig. 1) [2, 3, 10, 12-21]. Most patients had the p.G2019S mutation (22/38), but some carried the p.I2020T (8/38), p.R1441C (4/38), p.Y1699C (3/38), or p.R1441G (1/38) mutation. Twenty-eight patients had typical levodopa-responsive parkinsonism, whereas others had parkinsonism with levodopa resistance (1/38), supranuclear gaze palsy (1/38), muscular atrophy (1/38), dementia (3/38), or autonomic dysfunction (4/38); one patient had only dementia and tremor.

All patients displayed neuronal loss and gliosis in the substantia nigra. In 20 patients, pathology was deemed compatible with that of idiopathic PD (brainstem or transitional Lewy body disease - LBD, with or without moderate numbers of cortical LB), with concurrent Alzheimer's disease (AD) pathology in 3 of them (fig. 1). Interestingly, the second most common pathology was 'pure' nigral degeneration with no LB, displayed by 12 patients carrying the p.I2020T mutation (6/12) or the p.Y1699C
(2/12), p.G2019S (2/12), p.R1441C (1/12), or p.R1441G $(1 / 12)$ mutation (fig. 1$)$. In the p.R1441C carrier previously reported to have 'pure' nigral degeneration [2], we found that the ubiquitin-positive cytoplasmic inclusions in the nigra were positive for transactive response DNAbinding protein 43 (TDP-43), a feature that has not been emphasized in previous studies (fig. 1). In other patients, predominant pathological features included diffuse LBD (DLBD) (2/38), tau-positive neurofibrillary tangles reminiscent of PSP pathology (2/38), $\alpha$-synuclein-positive glial cytoplasmic inclusions compatible with multisystem atrophy (MSA) (1/38), and ubiquitin-positive pathology suggestive of frontotemporal dementia (FTLD-U; 1/38). The most striking intrafamilial variability was observed in family D with the Lrrk2 p.R1441C mutation, with brainstem LBD (BLDB), DLBD, PSP-like pathology, and nigral degeneration with ubiquitin-/TDP-43-positive cytoplasmic inclusions (fig. 1) [2,3]. Most patients from the Sagamihara family with the Lrrk2 p.I2020T mutation had 'pure' nigral degeneration $(n=6)$; however, one patient had MSA pathology and another one BLBD [16]. 


\section{From Gene to Disease}

$L R R K 2$ is a $144-\mathrm{kb}$ gene with 51 exons that encodes a 2,527 amino-acid multidomain protein. The physiologic function of Lrrk2 remains largely unknown, but experimental evidence suggests it may play a role in neuritic outgrowth and branching [22]. Immunohistochemistry studies in mice and humans have shown that Lrrk2 is mostly a cytoplasmic protein that is widely expressed in the brain and in other organs [17, 23]. While full-length Lrrk 2 is not a major component of LB, recent studies have shown that truncated forms of Lrrk 2 can be identified within LB, suggesting a potential role in protein aggregate formation [21]. Pathogenic mutations and genetic risk factors are located in the functionally relevant and highly conserved Roc, COR, MAPKKK and WD40 Lrrk2 domains. In vitro assays have shown that mutations located in the Roc and MAPKKK domains enhance Lrrk2 autophosphorylation, consistent with an autosomal dominant 'gain-of-function' pathogenic mechanism with increased kinase activity [24]. However, not all experimental data fit this model, which does not provide an explanation for mutations located in the COR and WD40 domains $[22,25]$.

Understanding the mechanisms that lead to neurodegeneration in LRRK2 mutation carriers poses several challenging questions. The widespread expression of the Lrrk 2 protein contrasts with the prominent vulnerability of select neuronal populations such as the nigrostriatal system, suggesting interactions with other molecules displaying regional specificity. Moreover, the significant clinical and pathologic phenotypic variability found in $L R R K 2$ mutation carriers supports the notion that Lrrk2 acts upstream of other proteins implicated in neuronal death, and that additional genetic, environmental and stochastic factors determine the type of pathology that develops in a given individual $-\alpha$-synuclein, tau, or ubiquitin/TDP-43 positive $[2,19,22]$. The p.R1441 residue may be associated with tau pathology as one patient with the Lrrk2 p.R1441C mutation had supranuclear gaze palsy and PSP-like pathology (fig. 1), and one p.R1441H carrier evolved into clinical PSP $[2,11]$. Furthermore, the lack of specific protein aggregation in some LRRK2 mutation carriers indicates that other pathways exist, which may include accumulation of proteins such as TDP-43 which was identified in one of our patients. Of note, half of the patients with 'pure' nigral degeneration harbor the Lrrk2 p.I2020T mutation, which, in contrast to p.G2019S, was shown to reduce Lrrk2 kinase activity [25]. This may suggest that increased Lrrk2 kinase activity triggers $\alpha$-synuclein aggregation and LB formation, whereas reduced kinase activity induces nigral degeneration through other pathways. Alternatively, some of the clinical and pathological phenotypes observed may represent incidental co-occurrence of other diseases unrelated to specific $L R R K 2$ mutations. Such hypothesis may be valid for individuals with pathology reminiscent of MSA, PSP, AD or FTLD-U; however, it would not account for those patients with 'pure' nigral degeneration.

\section{Conclusions}

Although recent advances in the genetics of PD have provided mechanistic hypotheses for neurodegenerative pathways, a thorough understanding of disease pathogenesis will require further studies addressing the critical issues of selective vulnerability and genotype-phenotype correlation. The clinical and pathological data reviewed herein suggest specific mutations may be associated with alternative PSP-like or 'pure' nigral degeneration phenotypes. A different effect on Lrrk2 kinase activity may play a role in such heterogeneity.

\section{Acknowledgements}

Mayo Clinic Jacksonville is a Morris K. Udall Parkinson's Disease Research Center of Excellence (NINDS P50 No. NS40256; D.W.D., Z.K.W.). Z.K.W. is also partially funded by P01 AG017216, R01 NS057567, R01 AG015866, Pacific Alzheimer Research Foundation grant C06-01, and CIHR 121849. C.W. is supported by the Swiss National Science Foundation (PASMP3-123268/1).

References paradigm shifts and future prospects. Nat Rev Genet 2006;7:306-318.

-2 Zimprich A, Biskup S, Leitner P, Lichtner P, Farrer M, Lincoln S, Kachergus J, Hulihan M, Uitti RJ, Calne DB, Stoessl AJ, Pfeiffer RF, Patenge N, Carbajal IC, Vieregge P, Asmus F, Muller-Myhsok B, Dickson DW, Meitinger T, Strom TM, Wszolek ZK, Gasser T: Mutations in LRRK2 cause autosomal-dominant parkinsonism with pleomorphic pathology. Neuron 2004;44:601-607.

- 3 Wszolek ZK, Pfeiffer RF, Tsuboi Y, Uitti RJ, McComb RD, Stoessl AJ, Strongosky AJ, Zimprich A, Muller-Myhsok B, Farrer MJ, Gasser T, Calne DB, Dickson DW: Autosomal dominant parkinsonism associated with variable synuclein and tau pathology. Neurology 2004;62:1619-1622. 
4 Ross OA, Toft M, Haugarvoll K: Corticobasal syndrome and primary progressive aphasia as manifestations of lrrk2 gene mutations. Neurology 2008;71:303; author reply 303-304.

5 Healy DG, Falchi M, O’Sullivan SS, Bonifati V, Durr A, Bressman S, Brice A, Aasly J, Zabetian CP, Goldwurm S, Ferreira JJ, Tolosa E, Kay DM, Klein C, Williams DR, Marras C, Lang AE, Wszolek ZK, Berciano J, Schapira AH, Lynch T, Bhatia KP, Gasser T, Lees AJ, Wood NW: Phenotype, genotype, and worldwide genetic penetrance of LRRK2-associated Parkinson's disease: a case-control study. Lancet Neurol 2008;7:583-590.

-6 Di Fonzo A, Wu-Chou YH, Lu CS, van Doeselaar M, Simons EJ, Rohe CF, Chang HC, Chen RS, Weng YH, Vanacore N, Breedveld GJ, Oostra BA, Bonifati V: A common missense variant in the LRRK2 gene, Gly2385Arg, associated with Parkinson's disease risk in Taiwan. Neurogenetics 2006; 7:133-138.

$\checkmark 7$ Ross OA, Wu YR, Lee MC, Funayama M, Chen ML, Soto AI, Mata IF, Lee-Chen GJ, Chen CM, Tang M, Zhao Y, Hattori N, Farrer MJ, Tan EK, Wu RM: Analysis of Lrrk2 R1628P as a risk factor for Parkinson's disease. Ann Neurol 2008;64:88-92.

8 Wszolek ZK, Pfeiffer B, Fulgham JR, Parisi JE, Thompson BM, Uitti RJ, Calne DB, Pfeiffer RF: Western Nebraska family (family D) with autosomal dominant parkinsonism. Neurology 1995;45:502-505.

$>9$ Wszolek ZK, Vieregge P, Uitti RJ, Gasser T, Yasuhara O, McGeer P, Berry K, Calne DB, Vingerhoets FJ, Klein C, Pfeiffer RF: German-Canadian family (family A) with parkinsonism, amyotrophy, and dementia longitudinal observations. Parkinsonism Relat Disord 1997;3:125-139.

-10 Chen-Plotkin AS, Yuan W, Anderson C, McCarty Wood E, Hurtig HI, Clark CM, Miller BL, Lee VM, Trojanowski JQ, Grossman M, Van Deerlin VM: Corticobasal syndrome and primary progressive aphasia as manifestations of LRRK2 gene mutations. Neurology 2008;70:521-527.
11 Spanaki C, Latsoudis H, Plaitakis A: LRRK2 mutations on Crete: $\mathrm{R} 1441 \mathrm{H}$ associated with PD evolving to PSP. Neurology 2006;67: 1518-1519.

-12 Dachsel JC, Ross OA, Mata IF, Kachergus J, Toft M, Cannon A, Baker M, Adamson J, Hutton M, Dickson DW, Farrer MJ: Lrrk2 G2019S substitution in frontotemporal lobar degeneration with ubiquitin-immunoreactive neuronal inclusions. Acta Neuropathol 2007;113:601-606.

13 Rajput A, Dickson DW, Robinson CA, Ross OA, Dachsel JC, Lincoln SJ, Cobb SA, Rajput ML, Farrer MJ: Parkinsonism, Lrrk2 G2019S, and tau neuropathology. Neurology 2006;67: 1506-1508.

14 Gaig C, Ezquerra M, Marti MJ, Valldeoriola F, Munoz E, Llado A, Rey MJ, Cardozo A, Molinuevo JL, Tolosa E: Screening for the LRRK2 G2019S and codon-1441 mutations in a pathological series of parkinsonian syn dromes and frontotemporal lobar degeneration. J Neurol Sci 2008;270:94-98.

15 Gaig C, Marti MJ, Ezquerra M, Rey MJ, Cardozo A, Tolosa E: G2019S LRRK2 mutation causing Parkinson's disease without Lewy bodies. J Neurol Neurosurg Psychiatry 2007; 78:626-628

16 Hasegawa K, Stoessl AJ, Yokoyama T, Kowa H, Wszolek ZK, Yagishita S: Familial parkinsonism: study of original Sagamihara PARK8 (I2020T) kindred with variable clinicopathologic outcomes. Parkinsonism Relat Disord 2009;15:300-306.

$>17$ Giasson BI, Covy JP, Bonini NM, Hurtig HI, Farrer MJ, Trojanowski JQ, Van Deerlin VM Biochemical and pathological characterization of Lrrk2. Ann Neurol 2006;59:315-322.

18 Gilks WP, Abou-Sleiman PM, Gandhi S, Jain S, Singleton A, Lees AJ, Shaw K, Bhatia KP. Bonifati V, Quinn NP, Lynch J, Healy DG, Holton JL, Revesz T, Wood NW: A common LRRK2 mutation in idiopathic Parkinson's disease. Lancet 2005;365:415-416.
19 Ross OA, Toft M, Whittle AJ, Johnson JL, Papapetropoulos S, Mash DC, Litvan I, Gordon MF, Wszolek ZK, Farrer MJ, Dickson DW: Lrrk2 and Lewy body disease. Ann Neurol 2006;59:388-393.

20 Khan NL, Jain S, Lynch JM, Pavese N, AbouSleiman P, Holton JL, Healy DG, Gilks WP, Sweeney MG, Ganguly M, Gibbons V, GandhiS, Vaughan J, Eunson LH, Katzenschlager R, Gayton J, Lennox G, Revesz T, Nicholl D, Bhatia KP, Quinn N, Brooks D, Lees AJ, Davis $\mathrm{MB}$, Piccini $\mathrm{P}$, Singleton $\mathrm{AB}$, Wood NW: Mutations in the gene LRRK2 encoding dardarin (PARK8) cause familial Parkinson's disease: clinical, pathological, olfactory and functional imaging and genetic data. Brain 2005;128:2786-2796.

21 Santpere G, Ferrer I: LRRK2 and neurodegeneration. Acta Neuropathol 2009;117:227246

22 Devine MJ, Lewis PA: Emerging pathways in genetic Parkinson's disease: tangles, Lewy bodies and LRRK2. FEBS J 2008;275:57485757.

23 Melrose HL, Kent CB, Taylor JP, Dachsel JC, Hinkle KM, Lincoln SJ, Mok SS, Culvenor JG, Masters CL, Tyndall GM, Bass DI, Ahmed Z, Andorfer CA, Ross OA, Wszolek ZK, Delldonne A, Dickson DW, Farrer MJ: A comparative analysis of leucine-rich repeat kinase 2 (Lrrk2) expression in mouse brain and Lewy body disease. Neuroscience 2007; 147:1047-1058.

24 West AB, Moore DJ, Choi C, Andrabi SA, Li X, Dikeman D, Biskup S, Zhang Z, Lim KL, Dawson VL, Dawson TM: Parkinson's disease-associated mutations in LRRK2 link enhanced GTP-binding and kinase activities to neuronal toxicity. Hum Mol Genet 2007; 16:223-232.

25 Jaleel M, Nichols RJ, Deak M, Campbell DG, Gillardon F, Knebel A, Alessi DR: LRRK2 phosphorylates moesin at threonine-558: characterization of how Parkinson's disease mutants affect kinase activity. Biochem J 2007;405:307-317. 